\title{
DILEMAS DE UMA GERAÇÃO: a juventude líquida e as novas composições significativas das práticas sociais
}

Rodolfo Rodrigo Santos Feitosa79

\section{Resenha do livro:}

BAUMAN, Zygmunt.; LEONCINI, Thomas. Nascidos em tempos líquidos. Rio de Janeiro: Zahar, 2018.

Passados pouco mais de um ano da morte de Zygmunt Bauman (19252017), chega ao Brasil o livro Nascidos em tempos líquidos. Fruto de parceria com o jovem jornalista italiano Thomas Leoncini, esta obra foi construída a partir da troca de correspondências entre ambos, apresentando-se como uma leitura enxuta e precisa de alguns dos dilemas que marcam toda uma geração, cujo universo relacional foi a modernidade liquida. O texto possui notória leveza e fácil apreensão por parte do leitor, distinguindo-se de outras produções em que a sociologia de Bauman é destacadamente marcada pela densidade analítica. A linguagem direta e atraente na abordagem das circunstâncias tangentes à realidade dos indivíduos da "geração líquida" facilitou o enquadramento das questões no prisma da teoria social. Com isso o texto torna-se passivel de uma aceitação bem mais ampla entre leitores de outras áreas que não estritamente as ciências sociais.

A brevíssima nota escrita por Alekssandra Kania Bauman cumpre o papel de "apresentação", convidando-nos à leitura de um escrito em que o sociólogo polonês reitera sua atenção para com a juventude e as suas problemáticas inerentemente atreladas ao contexto da liquidez. Dividida em três capítulos construidos dialogicamente, a obra aborda mudanças marcantes que

79 Docente do Instituto Federal de Educação, Ciência e Tecnologia do Sertão Pernambucano. ORCID: http://orcid.org/0000-0002-0484-154X. Email: rrfeitosa@gmail.com. 
caracterizam as formas plurais e complexas das práticas sociais dessa referida geração, particularmente a respeito dos seguintes eixos: usos e apropriações simbólico-identitárias do corpo; bullying e comportamento agressivo; e os novos padrões de relacionamentos sexuais e amorosos.

Considerando que "[...] os jovens são a fotografia dos tempos que mudam", Bauman e Leoncini (2018, p. 13) despertam o nosso olhar para os sentidos mais profundos conectados aos movimentos que, pela ambivalência da modernidade, restituem práticas sociais em novas composições significativas, identitárias e relacionais. No primeiro capítulo, ao tratar das emulações do corpo existentes atualmente, os autores recuperam, a partir de Ferdinand Tönnies, Georg Simmel e Erick Hobsbawm, os pressupostos histórico-sociológicos das modificações que cingiram a passagem de uma práxis social a uma práxis da identificação. Neste sentido, tal movimento captura parte da tensão recente entre comunidade e identidade na forja do pertencimento social. Sob esta ótica, as emulações corporais passaram a refletir os dilemas pertinentes à conciliação entre "autodefinição" e "autoafirmação" em uma circunstância bastante peculiar da modernidade, na qual paralelamente à individualização da esfera pública ocorre a proeminência das efêmeras formas-consumo modais.

Nessa dialética da moda, narrativas corporais como a barba do hipster, as tatuagens, os piercings, e mesmo as "intervenções cosmético-farmacêuticocirúrgicas" assinalam, cada qual à sua medida, os termos das escolhas identitárias em uma sociedade de consumidores. Dentre tais formas emulativas de alteração corpórea, os procedimentos cosmético-farmacêuticos, postos em prática pelo milagre da medicina contemporânea, possuem uma economia diferenciada, a qual se ancora fundamentalmente no "[...] mágico estratagema de transformar a possibilidade em obrigação" (BAUMAN; LENCIONI, 2018, p. 30). Uma das repercussões práticas desse cenário é o crescente número de jovens que se submetem a cirurgias plásticas com fins exclusivamente estéticos, orientados por um desejo de adequação a padrões (quase sempre) ditados pela moda e, não raro, incisivamente mais requeridos às mulheres. Para Leoncini, em termos gerais, esse quadro sugere uma propensão da ampliação do consumo para a estética 
corporal afim com a lógica da práxis de identificação. Ao contrário, Bauman vislumbra em tais práticas de consumo tendências que ainda não se consolidaram efetivamente, e cujos dados citados pouco permitiriam em termos de generalizações, a revelia do que sustenta seu interlocutor.

$\mathrm{Na}$ segunda parte do livro emergem as reflexões pertinentes às mutações da agressividade que culminaram com a conformação do bullying enquanto prática social detentora de significados particulares. Recuperando elementos da antropologia de Arnold Van Gennep e da historiografia social de Norbert Elias, Leoncini e Bauman debatem inicialmente acerca do caráter do bullying, um pensando-o como rito de passagem, e o outro sugerindo lê-lo sob a perspectiva da agressividade que, volta e meia, escapa à contenção posta pelo processo civilizador. Mesmo não se formando um consenso a esse respeito, os autores concordam que a prática em si revela "necessidades" culturais mais profundas, tangentes à própria definição do "eu" em termos identitários.

Indagado se já havia sofrido bullying, Bauman utiliza sua narrativa pessoal de vítima desse tipo de prática para explicitar o seu teor mais profundo. Já de posse dos conhecimentos sociológicos adquiridos em sua formação, diz ele, "dei-me conta de que designar um inimigo e demonstrar a todo custo a inferioridade dele era a inseparável outra face da medalha da identificação do eu. Não existe um 'nós' sem um 'eles'" (BAUMAN; LEONCINI, 2018, p. 46). Não por acaso, as vitimas desse tipo de comportamento hostil revelam matizes de segregações sociais, culturais, econômicas, étnicas e de gênero, manifestas ou veladas também em outras instâncias sociais. De acordo com o relato, o fato de ser judeu fez de Bauman (e mais outros dois colegas seus) alvo persistente de ações desse tipo nos tempos em que estudava na Polônia. A narrativa recuperada pelo sociólogo é colocada ao lado de outros depoimentos de vítimas, apresentados por Leoncini, servindo, assim, exemplificativamente à análise. Por outro viés, é possivel que também repercuta positivamente na relação de empatia entre leitores e autores, na medida em que exala a sensibilidade para com a questão discutida. 
Enquanto uma espécie de violência social em prol da reafirmação identitária, nada haveria de excepcional sobre o tipo de conduta que é o bullying, sendo mesmo recorrente na história como forma de marcação e distinção entre os individuos. Excetuam-se, contudo, as manifestações típicas da atualidade como merecedoras de considerações à parte, principalmente em decorrência de suas expressas associações com a "banalização do mal", assim como à "insensibilidade social" perante ocorrências com essa natureza perversa. A fala de Bauman, especialmente, tenta ilustrar uma densa mutação na percepção moral da sociedade líquida, a qual, no geral, convive como espectadora do mal banalizado, sem constituir a seu respeito qualquer tipo de constrangimento profundo. Simultaneamente, diminuem em intensidade e quantidade as consternações para com aqueles que são vitimados por essas violências banais.

Sob a rubrica do mal banalizado, cuja maior arma revela-se a condescendência de uma sociedade crescentemente insensivel, o bullying da geração líquida distancia-se fortemente do tipo de significado que possuía outrora. A "rejeição" de um "outro" conduzida preferencialmente com fins de identificação do "eu" sai de cena, ao passo que o espetáculo da violência casual despropositada se torna insistentemente recorrente, contrariando mesmo a lógica da causa e efeito em episódios sucessivos de ódio injustificado. Não fosse isso por si só deveras preocupante, elevamos ainda mais a mancha moral em virtude dessas circunstâncias na medida em que "[...] estamos calmamente nos adaptando a esse estado de coisas ilógico, ou melhor, totalmente inconcebivel (BAUMAN; LEONCINI, 2018, p. 56)". Assim, os autores apontam que, ao contrário do que se esperaria, a repercussão lastimável disso tudo é o nosso propenso conformismo com a condição de espectadores, daquilo que parece ser mais uma cena da tragédia moral na modernidade líquida.

A essa altura da obra o debate pretende nos chamar atenção para a importância de refutar o papel de telespectador, cuja adesão maciça de nossa parte ocorre em prol da conveniência e do conforto. A aceitação da violência descabida e aleatória dá margem a uma fenda social preocupante refletida na descaracterização significativa do bullying No escopo de sua manifestação 
"normal", registrada pelas páginas de antropólogos, psicólogos e historiadores, essa forma de violência dirigida ao "outro", a qual goza de relativa tolerância social, seria uma das modalidades (dentre outras existentes) de dar vazão a nossa agressividade contida. O problema é que em sua nova versão líquida, o bullying deixou de operar detidamente a "identificação do eu" e direciona-se especialmente à reiteração de violências sem cabimentos, fragmentando o tecido social e expondo a distorção moral dos nossos tempos.

Tendo como foco as relações amorosas em tempos de volatilidade, o terceiro e último capítulo constata o declínio dos tabus e o predomínio das interações no mundo virtual como marcas indeléveis e emblemáticas do surgimento de novas formas de envolvimento intimo, bem como de diferentes modalidades de realização sexual. O exuberante mundo on-line se configura não apenas, mas majoritariamente, enquanto campo de satisfação pessoal, individualizado, por assim dizer. Nesse universo de conexões instrumentalmente instantâneas, os âmbitos amorosos e sexuais são parte constituinte e em expansão, cuja forma de apresentação assume quase sempre o caráter de "oferta de produtos" (logo, configuráveis tanto quanto descartáveis).

$\mathrm{Na}$ visão dos autores, o delineamento assumido pelas relações no mundo virtual acaba negando o seu imenso potencial democrático, possivel pelo alargamento do espaço público. À serviço do "eu", a instrumentalização dos laços opera como regra, salvo quando a ela é interposta a negociação por parte do "outro", cujo enquadramento interpretativo sugerido por Bauman remonta à dialética segurança/liberdade. Nessa linha, as dinâmicas de gênero atuais reportam muito mais a pauta da paridade dos sexos que o império de um sobre o outro, podendo ser captadas como formas alternativas à apropriação instrumental daqueles com quem se relaciona. De qualquer forma, o modus operandi que se faz dominante no meio virtual tende a reduzir a seara pública aos interesses individuais. O diálogo, a exposição do contraditório e a concertação perdem a significância no universo virtual de relações e interações construídas criteriosa e seletivamente para o gozo de individualidades. 
Atendendo a padrões de flexibilidade, conveniência e ainda a certos graus de anonimato (quando desejável), os relacionamentos virtuais efêmeros se proliferam à maré da decrepitude de antigos padrões de envolvimento que, assentados em compromissos de médio/longo prazo, soam exaustivos e dispendiosos. Ao jovem de hoje, portanto, parece de fato incompatível com seus anseios, e mesmo indesejável, a opção por uma relação amorosa fixa, pois embora esse tipo de relacionamento oferte-lhe segurança, o que requer em troca pesa negativamente ao seu favor. Como alertado em outro instante, "entre as artes da vida líquido-moderna e as habilidades necessárias para praticá-las, livrar-se das coisas tem prioridade sobre adquiri-las" (BAUMAN, 2007, p.8). Ora, em uma realidade social de hiperestímulos, na qual tempo e dedicação são recursos valiosíssimos utilizados na fruição dos prazeres, assumir um relacionamento permanente com um único parceiro(a) contraria a própria lógica hedonista que rege boa parte das escolhas afetivas hodiernas.

Essa reflexão culmina com a ideia de que a volatilidade e a indeterminação dos tempos líquidos são incongruentes com o excessivo regramento e restrições comportamentais. Se em termos sociais mais amplos ao individuo de nossa época é requisitada a competência adaptativa, também acontece o mesmo no espectro amoroso, de tal sorte que a permanência de tabus afetaria o ajuste às mudanças em curso desde a segunda metade do século XX. De lá para cá, o espaço da "interdição" foi reduzido significativamente, mas não extinto por completo. A este respeito, Bauman e Leoncini (2018) pontuam que permanece o tabu do incesto antropologicamente vivo em nossa sociedade, "estruturando" padrões classificatórios e associativos, como outrora havia sinalizado LéviStrauss. Em meio a tudo isso, resta claro que similarmente ao mundo do trabalho, o imperativo vigente no sinuoso campo das relações amorosas contemporâneas é também o da flexibilidade.

Nessa perspectiva, no espaço relacional on-line é permitido ao indivíduo controlar os acessos à sua pessoa, igualmente, pode servir-lhe como refúgio à adversidade indesejada e/ou facultar-lhe a conexão/interação estrita com aqueles de seu interesse. Em contraste, no mundo off-line de contatos 
interpessoais diretos um tal poder the escaparia às mãos, sendo inevitável, na maior parte dos casos, a tarefa desagradável de comunicar-se com alguém que não se queira. Conciliar "equilibradamente" esses dois mundos e as expectativas que deles derivam é agora uma habilidade almejada pela maioria dos jovens da geração líquida, justamente porque possibilita melhores horizontes à realização pessoal no chão de incertezas e aparências em que pisam.

Em síntese, o livro trata de dilemas que afetam os jovens dos tempos líquido-modernos, evidenciando as transformações que essa época trouxe às cenas relacionais, às práticas sociais e às composições significativas presentes em outras versões nas formações sociais históricas. Sob o terreno tempestuoso da incerteza intrínseca, as modalidades emulativas de manipulação corporal, as interações interpessoais marcadas pela agressividade significada e os relacionamentos amorosos passaram a se constituir sobre quadros particulares de complexidade e tensão que configuram as vivências dos indivíduos da geração em questão. Para analisar tais assuntos, Bauman recorre oportunamente a argumentos fulcrais desenvolvidos ao longo de sua expressiva produção teórica. Esse expediente, cujo propósito didático é indiscutivel, esclarece as bases conceituais mínimas a partir das quais se torna inteligivel, do ponto de vista sociológico, as transformações em meio às quais a juventude contemporânea se posiciona.

Em virtude de sua natureza dialogada, o percurso comunicativo da obra assume, em seu escopo geral, o molde de indagações seguidas de explicações, mas não se reduz a tal desenho. Em repetidas passagens Bauman opta por quebrar a sequência dos questionamentos, dando preferência a novas considerações sem pretensões responsivas, mas que conduzem seu interlocutor a patamares mais profundos do tema em pauta. Em algumas ocasiões essa estratégia possivelmente soará desinteressante a quem já tenha perscrutado outros títulos de sua autoria como Amor Líquido, Medo Líquido, Vida líquida e Vida em Fragmentos. Isso porque a condução dos raciocínios desenvolvidos ancora-se em argumentos trabalhados nesses textos anteriores, o que torna um tanto previsivel o desfecho das ideias. 
O caráter mais informal do debate é um destaque, gerando a impressão de que tal apresentação fora intencionalmente formulada como artificio para cativar novos leitores, provavelmente jovens que entrariam em contato com o legado teórico do polonês a partir dessas páginas. Aliás, as ponderações sociológicas de Bauman encaixam-se bem às inquietações apresentadas por Leoncini, algumas destas ilustradas em exemplos formidavelmente atraentes a esse tipo possivel de público. Prova disso é a menção feita aos jogos eletrônicos que "simulam" interações afetivas entre pessoas reais e avatares virtuais idealizados, a qual serve alegoricamente à reflexão sobre a complexidade dos relacionamentos amorosos nos domínios do mundo on-line. A análise sugerida para tal circunstância tange à incompatibilidade das relações interpessoais permanentes diante do fluxo e intensidade de estímulos que atuam sobre os individuos contemporâneos. Em um tal panorama, a virtualização de relações amorosas atenderia ao conveniente do desapego, da fugacidade e do não comprometimento, uma vez que nas condições atuais dedicação soa como dispêndio pouco vantajoso. Lembremos a este respeito que "[...] ligações frouxas e compromissos revogáveis são os preceitos que orientam tudo aquilo em que se engajam e a que se apegam" os sujeitos do mundo liquido" (BAUMAN, 2007, p.11).

Ao final da leitura, não será incomum o leitor se deparar com a sensação de que a interlocução entre os autores se construiu sob a pintura de uma "tutela intelectual", evidenciada nas instruções e ressalvas dirigidas a Thomas Leoncini. O posfácio escrito pelo jornalista reforça essa ideia, na medida em que retrata seu respeito e agradecimento aos ensinamentos provindos da convivência e diálogo com o teórico da modernidade líquida. A emoção expressa nessas páginas finais acaba por reforçar a sensação de que a teoria social contemporânea de fato perdeu um de seus maiores e mais produtivos pensadores. Esta obra póstuma talvez seja um verdadeiro e atrativo convite deixado por Zygmunt Bauman aos jovens que compõem a geração líquida, sendo assim uma espécie de provocação à autorreflexão, cujo legado teórico por ele construído poderia auxiliá-los nesse movimento que se mostra imprescindivel face às condições da própria incerteza do futuro. 


\section{Referências}

BAUMAN, Z. Vida Líquida. Rio de Janeiro: Jorge Zahar Ed., 2007.

Recebido: 24 out. 2018

Aceito: 23 nov. 2018 